\title{
O protagonismo estudantil e os desafios da sociedade contemporânea: um diálogo
}

\section{sobre projeto de vida}

\author{
Student protagonism and the challenges of contemporary society: a dialogue on the project of life \\ El protagonismo estudiantil y los retos de la sociedad contemporánea: un diálogo sobre el proyecto \\ de vida
}

\author{
Sabrina Crisóstomo Rocha \\ ORCID: https://orcid.org/0000-0002-5437-9023 \\ Universidade Católica de Brasília, Brasil \\ E-mail: sassa08@gmail.com \\ Renato de Oliveira Brito \\ ORCID: https://orcid.org/0000-0002-9345-2529 \\ Universidade Católica de Brasília, Brasil \\ E-mail: renatoorios@gmail.com \\ Livia Maria Rassi Cerce \\ ORCID: https://orcid.org/0000-0001-8084-7129 \\ Universidade Católica de Brasília, Brasil \\ E-mail: profliviamaria2018@gmail.com
}

\begin{abstract}
Resumo
Este artigo apresenta os resultados de uma pesquisa que visa compreender se o desenvolvimento de um projeto de vida individual pode contribuir para o protagonismo estudantil de jovens e adolescentes do Ensino Médio. O estudo considera aspectos como autonomia, protagonismo, engajamento, responsabilidade, dos jovens frente aos desafios da sociedade contemporânea. Este estudo foi estruturado tendo por base as respostas obtidas por meio de um questionário aplicado a 21 estudantes do Ensino Médio. Essa investigação assume caráter qualitativo pautando-se nos procedimentos da Análise de Conteúdo. Todavia, as informações coletadas também foram interpretadas de forma quantitativa. Observou-se que estudantes do Ensino Médio que refletem sobre seu projeto de vida apresentam características desenvolvidas positivamente quanto ao engajamento, dedicação, motivação, postura frente ao cotidiano e formação da identidade. Não existe um momento exato para que o indivíduo tome direção na vida, mas um atraso na escolha dele pode acarretar desistência na procura de caminhos positivos, ausência de metas, descomprometimento com a carreira profissional e familiar.
\end{abstract}

Palavras-chave: Projeto de vida; Protagonismo estudantil; Autonomia.

\begin{abstract}
This article presents the results of a research that aims to understand whether the development of an individual life project can contribute to the student participation of high school youth and adolescents. The study considers aspects such as autonomy, protagonism, engagement, responsibility, of young people facing the challenges of contemporary society. This study was structured based on the answers obtained through a questionnaire applied to 21 high school students. This investigation takes on a qualitative character, based on Content Analysis procedures. However, the information collected was also interpreted quantitatively. High School students who reflect on their life project have positively developed characteristics in terms of engagement, dedication, motivation, attitude towards daily life, identity formation. There is no exact moment for the individual to take direction in life, but a delay in choosing one can lead to giving up in the search for positive paths, lack of goals, lack of commitment to a professional career, life, family.
\end{abstract}

Keywords: Life project; Student protagonism; Autonomy.

\section{Resumen}

Este artículo presenta los resultados de una investigación que tiene como objetivo comprender si el desarrollo de un proyecto de vida individual puede contribuir a la participación estudiantil de jóvenes y adolescentes de secundaria. El estudio considera aspectos como la autonomía, el protagonismo, el compromiso, la responsabilidad, de los jóvenes ante los desafíos de la sociedad contemporánea. Este estudio se estructuró a partir de las respuestas obtenidas mediante un cuestionario aplicado a 21 estudiantes de secundaria. Esta investigación adquiere un carácter cualitativo, basado en procedimientos de Análisis de Contenido. Sin embargo, la información recopilada también se interpretó cuantitativamente. Se observó que los estudiantes de secundaria que reflexionan sobre su proyecto de vida tienen características desarrolladas positivamente en cuanto a compromiso, dedicación, motivación, actitud hacia la vida cotidiana y formación de identidad. No existe un momento exacto para que el individuo tome rumbo en la vida, pero un 
retraso en la elección puede llevarlo a rendirse en la búsqueda de caminos positivos, falta de metas, falta de compromiso con la carrera profesional y familiar.

Palabras clave: Proyecto de vida; Protagonismo estudiantil; Autonomía.

\section{Introdução}

Os jovens do século XXI convivem com o veloz avanço da ciência e tecnologia, estão conectados e acompanhando em tempo real o que acontece no mundo. Pode-se afirmar que, hoje, se vive em um mundo com incertezas. Nesse contexto, a Dell Technologies, que é uma família exclusiva de empresas oferece a infraestrutura essencial para as organizações construírem seu futuro digital, transformarem a TI e protegerem seus ativos mais importantes: as informações. A empresa atende clientes de todos os portes em 180 países - estabeleceu recentemente uma parceria com o Institute for the Future (IFTF) - O Institute for the Future (IFTF) é uma organização de pesquisa estratégica independente, sem fins lucrativos e de ensino com quase 50 anos de experiência em previsões.

A essência de seu trabalho consiste em identificar tendências emergentes e descontinuidades que transformarão a sociedade global e o mercado mundial. Sua pesquisa gera as previsões necessárias para criar percepções que resultam em ações, além de abranger um amplo território de panoramas futuros profundamente transformadores, desde saúde e assistência médica até tecnologia, local de trabalho, aprendizado e identidade humana - e 20 especialistas de todo o mundo para projetar o futuro, prever como as tecnologias emergentes - como AI (Artificial Intelligence, inteligência artificial) e IoT (Internet of Things, Internet das coisas), promoveu um estudo denominado Concretizando 2030: o futuro do trabalho, que deverá alterar a forma como vivemos e trabalhamos até 2030, além de coletar percepções que ajudarão as empresas a cruzar a próxima década.

Os especialistas concluíram que estamos no vértice da próxima era de parcerias entre pessoas e máquinas. Além disso, apontam sobre o futuro de parcerias entre pessoas e máquinas e analisam os impactos das tecnologias até 2030. A pesquisa, teve a participação de 3800 líderes de negócios de médias e grandes corporações em 17 países, incluindo o Brasil, e estima que 85\% dos trabalhos que existirão em 2030 serão novos.

Os jovens precisam estar preparados para lidar com os avanços e incertezas do presente e futuro, uma vez que as competências do futuro demandarão ações para os quais eles, muitas vezes, não estão preparados, como a cultura colaborativa, a inteligência emocional, inovação, resolução de problemas complexos, comunicação, negociação, liderança. Ações que incentivem a criatividade, o acompanhamento das tendências e lidar com as expectativas pessoais podem ser caminhos que auxiliarão os jovens nas incertezas futuras.

O método tradicional de ensino, com o objetivo de universalizar a educação para qualificar e alfabetizar a população para exercer uma profissão, é adotado no Brasil desde meados dos anos 60. Esse método se caracteriza pela centralidade da aprendizagem no professor, ou seja, o educador transmite o conhecimento e o aluno guarda, armazena a informação. Entende-se aqui que esse tipo de relação não é oportuna para o perfil de estudante da sociedade atual por que não atende às demandas da contemporaneidade e que o futuro exige.

Segundo Freire (1987, p.58) no ensino tradicional o professor,

[...] conduz os educandos à memorização mecânica do conteúdo narrado. Mais ainda, a narração os transforma em "vasilhas", em recipientes a serem "enchidos" pelo educador. Quanto mais vá "enchendo" os recipientes com seus “depósitos”, tanto melhor educador será. Quanto mais se deixem docilmente “encher”, tanto melhores educandos serão.

Essa citação freireana reafirma que a metodologia tradicional de ensino não favorece a construção do saber do estudante. Ele não desenvolve a criatividade e a criticidade sobre os diversos conteúdos conceituais desenvolvidos, pois há a alienação e a dominação da educação. É preciso entender que o ensinar não se restringe ao conhecimento dos conteúdos específicos das 
disciplinas, isso é apenas um dos aspectos desse processo. Hoje, é possível aprender em qualquer lugar, a qualquer hora, com pessoas diferentes, cursos, materiais diversos. A informação "cabe” na palma da mão.

Para Dowbor (2013, p. 21): “Atualmente, a sociedade é conhecida como a sociedade do conhecimento”, ela está baseada em competências cognitivas, pessoais e sociais, portanto exige dos indivíduos proatividade, colaboração, visão empreendedora. Essas competências são desenvolvidas quando o estudante está ativo no processo de ensino aprendizagem e o professor cria espaços para a reflexão, investigação, crítica, criatividade, desafios.

Deste novo perfil de estudantes, surge a importância de se repensar a formação de professores para conduzir a dinâmica de sala de aula e proporcionar ambientes de conhecimentos. Assim, para Freire (2015, p. 30),

[...] a ação do professor mediador perpassa o ensino de conceitos puramente memorísticos, pois percebe-se que, faz parte das atribuições do educador educar para: o mérito da paz com que viva a certeza de que faz parte de sua tarefa docente não apenas ensinar os conteúdos, mas também ensinar a pensar certo. Daí a impossibilidade de vir a tornar-se um professor crítico se, mecanicamente memorizador, é muito mais um repetidor de frases e de ideias inertes do que um desafiador.

O professor mediador é o articulador das atividades coletivas e individuais. Ele é o responsável por acompanhar, mediar, analisar os processos, necessidades, a partir dos percursos realizados pelos estudantes. Cabe a ele também construir propostas centradas no aluno, na colaboração e personalização. Deste modo, compete ao professor, desenvolver uma prática educativa pautada no diálogo, em que a construção do conhecimento deve se dar numa relação, em que o professor e o estudante reflitam sobre o objeto do conhecimento para que a aprendizagem seja desenvolvida.

Há a urgência de reinventar a escola de modo que seja possível preparar crianças e jovens para uma sociedade diferente, nova e incerta. Fava (2018) afirma que necessitaremos de pessoas com braços estendidos, capazes de sonhar, que tenham os pés na terra e a cabeça nas nuvens; idealistas, qualificadas para transformar sonhos em visão de futuro; suficientemente práticas para torná-los realidade; determinadas, que não tenham metamorfoses, mas saibam tirar proveito delas. Para o presente e futuro, podese afirmar que ter consciência e buscar um propósito, a missão de vida, a razão de existir será o diferencial para a vida de crianças e jovens.

A sociedade contemporânea exige que os processos de ensino e aprendizagem sejam mais dinâmicos, necessitando de um novo perfil docente. É preciso entender que o ensinar não se restringe ao conhecimento dos conteúdos específicos dos componentes curriculares, isso é apenas um dos aspectos desse processo, é necessário incentivar a autonomia dos estudantes, fazer com que eles percebam seu papel como protagonistas do processo, encorajando iniciativas e com comunicações não controladoras.

Segundo Reeve (2009),

Os estudantes que se percebem autônomos em suas interações escolares apresentam resultados positivos em relação: 1 - à motivação (apresentando motivação intrínseca, a percepção de competência, pertencimento, curiosidade, internalização de valores); 2- ao engajamento (com emoções positivas, persistência, presença nas aulas, não reprovam ou se evadem da escola); 3- ao desenvolvimento (evidenciando autoestima, autovalor, preferência por desafios ótimos, criatividade); 4- à aprendizagem (melhor entendimento conceitual, processamento profundo de informações, uso de estratégias autorreguladas); 5- à melhoria do desempenho em notas, nas atividades, nos resultados em testes padronizados); e 6-ao estado psicológico (apresentando indicadores de bem-estar, satisfação com a vida, vitalidade).

Neste sentido, é importante que os professores valorizem dos saberes já construídos, buscando uma postura reflexiva, investigativa e crítica de seus estudantes.

De acordo com Bassalobre (2013, p. 14), 
É possível inferir que, em oposição às experiências pedagógicas "sólidas" e conteudistas, as atuais demandas sociais exigem do docente uma nova postura e o estabelecimento de uma nova relação entre este e o conhecimento, uma vez que cabe a ele, primordialmente, a condução desse processo. Com efeito, essas exigências implicam em novas aprendizagens, no desenvolvimento de novas competências, em alteração de concepções, ou seja, na construção de um novo sentido ao fazer docente, imbuído das dimensões ética e política.

Partindo da premissa desse autor, a educação e seus processos de ensino, não é difícil compreender que o conhecimento dos conteúdos específicos dos componentes curriculares por si só, não são capazes de formar um cidadão integral para o novo modelo de sociedade.

Diante do exposto, esta pesquisa se justifica por buscar compreender o perfil do estudante e as características da sociedade contemporânea, para se afirmar a importância do desenvolvimento de um projeto de vida por este jovem e adolescente. Assim, a pesquisa relaciona o estudante, os desafios da sociedade contemporânea e a importância do projeto vital.

\section{Protagonismo Estudantil}

De acordo com o Conselho Nacional da Juventude (CONJUVE), são considerados jovens os sujeitos com idade compreendida entre 15 e os 29 anos, sendo que a noção de juventude não pode ser reduzida à um recorte etário. Os estudantes do ensino médio, em geral, são jovens e adolescentes. Segundo Klein (2011), a adolescência aborda uma etapa da vida do ser humano que compreende as transformações fisiológicas, afetivas e cognitivas, relacionadas a psicologia, enquanto a juventude, analisada no aspecto sociológico e antropológico, compreende a fase de transitoriedade da infância para a idade adulta marcada por decisões fortemente influenciadas pelo âmbito cultural, social e econômico.

"A adolescência é a transição no desenvolvimento que envolve mudanças físicas, cognitivas, emocionais e sociais e assume formas variadas em diferentes contextos sociais, culturais, e econômicos." (Feldman e Papalia, 2013, p. 386).

$\mathrm{Na}$ adolescência ocorrem transformações nas estruturas de pensamento e na afetividade, esta fase possibilita que os sujeitos se desliguem do imediato, do concreto e elaborem mentalmente situações idealizadas, de onde emerge o desejo de transformar o mundo. Em situações concretas e reais os adolescentes consideram as possibilidades, construindo teorias, refletindo sobre o seu próprio pensamento mediante sua capacidade de reflexão e de fuga do concreto, em direção ao abstrato e ao possível. Essa capacidade permite ao adolescente sua integração moral e intelectual à sociedade dos adultos, proporcionando a elaboração de seu programa de vida e o planejamento de reforma.

Para Feldman e Papalia (2013, p. 387) “A adolescência oferece oportunidades para o crescimento não só em termos de dimensões físicas, mas também em competência cognitiva e social, autonomia, autoestima e intimidade. Os jovens que têm relações de apoio com os pais, a escola e a comunidade tendem a desenvolver-se de forma produtiva e saudável."

Segundo Boghossian e Minayo (2009, p.416) “o protagonismo pressupõe a criação de espaços de escuta e participação dos jovens em situações reais na escola, na comunidade e na vida social, tendo em vista tanto a transformação social como sua formação integral", nesse sentido entende-se que o protagonismo estudantil fomenta a participação e integração dos jovens em situações cotidianas, concretas, individuais ou em comunidade que estabeleçam ações de cidadania, atuando de forma criativa, construtivista e solidariamente na solução de problemas reais.

A Lei Complementar $n^{\circ} 1.164$ de janeiro de 2012 (BRASIL, 2012), definiu protagonismo juvenil como "processo atitudinal pelo qual os alunos, sob orientação dos professores, assumem progressivamente a gestão de seus conhecimentos e de sua aprendizagem, com responsabilidade individual, responsabilidade social e responsabilidade institucional..." diante do que a lei apresenta, é possível compreender que o conceito de protagonismo juvenil favorece o empoderamento dos jovens diante dos desafios enfrentados no presente e como preparação para o que virá no future. 


\section{Projeto de Vida}

No intuito de promover o protagonismo dos estudantes do ensino médio, dentre outras iniciativas, surgiu o projeto de vida, que segundo Damon (2009, p. 43)

“Trata-se de uma preocupação suprema. É a máxima resposta à questão por quê? Por que está fazendo isso? Por que isso tem importância para você? Um projeto vital é uma razão mais profunda para os objetivos e motivos imediatos que orientam a vida cotidiana!"

O projeto de vida permite que o indivíduo decida sobre a própria existência com autonomia e comprometimento. O projeto de vida permite o sonho, o planejamento, a organização de pensamentos, de ações, escolhas, valores pessoais e coletivos, que se viva em um movimento de construção e reconstrução do eu, a partir de metas e objetivos que nortearão o sentido da vida. Considerando a vida e as infinidades de possibilidades em seus diversos âmbitos que constantemente estão em modificação, pressupõe-se a construção e reconstrução do projeto de vida individual, neste sentido Freire (2014, p. 51 e 52) sinaliza que:

"Na verdade, o inacabamento do ser ou sua inconclusão é próprio da existência vital. Onde há vida, há inacabamento. Mas só entre mulheres e homens o inacabamento se tornou consciente. (...) Gosto de ser gente, porque sei que minha passagem pelo mundo não é predeterminada, preestabelecida. Que o meu 'destino' não é um dado, mas algo que precisa ser feito e de cuja responsabilidade não posso me eximir. Gosto de ser gente porque a história em que me faço com os outros e de cuja feitura tomo parte é um tempo de possibilidade e não de determinismo".

Na citação, Freire sugere o sentido de inacabamento da construção e reconstrução do eu, ou seja, do projeto de vida que está em constante processo de criação, de redefinição. A dinamicidade é o que permite vitalidade à vida. É o que colore os traços cotidianos e contínuos de cada projeto.

\section{Projeto de vida e o protagonismo estudantil}

A educação da juventude no estabelecimento de um projeto de vida, tendo bases estruturante as discussões com os colegas, sendo protagonista de teorias reformadoras da realidade através do debate e as críticas dos outros levará a consciência dos limites das suas concepções. Esta interação de ideias emocionalmente conduzirá o jovem a sintetizar à realidade e a experiência, o que possibilitará a superação de um indivíduo idealista e sonhador a realizador, no sentido autêntico e concre to de suas decisões, como uma pessoa adulta. Estudos comprovam que cada vez mais os estudantes apresentam grandes dificuldades de aprendizagens, transtornos afetivos, conduta antissocial, baixa motivação e realização; uso de drogas, privação econômica.

Por este motivo a BNCC (BRASIL, 2018), propõe um ensino por competências, a fim de transpor a fragmentação do processo de ensino e aprendizagem, Dessa forma:

"Competência é definida como a mobilização de conhecimentos (conceitos e procedimentos), habilidades (práticas, cognitivas e socioemocionais), atitudes e valores para resolver demandas complexas da vida cotidiana, do pleno exercício da cidadania e do mundo do trabalho". (BRASIL, 2018, p.35)

Esse documento permite que o trabalho que fundamenta a prática pedagógica dos docentes, a partir do desenvolvimento de competências, oportunize ao estudante construir aspectos do seu projeto de vida.

Quando define as competências, a BNCC (BRASIL, 2018) reconhece que a "educação deve afirmar valores e estimular ações que contribuam para a transformação da sociedade, tornando-a mais humana, socialmente justa e, também, voltada para a preservação da natureza". Reafirmando assim, a capacitação do desenvolvimento do projeto de vida dos jovens e adolescentes, assim como permeando ações que ele seja protagonista. 


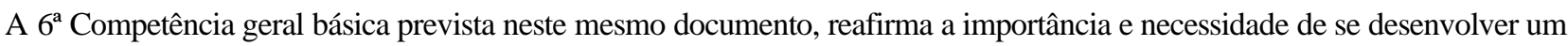
projeto de vida, em que o estudante assuma o protagonismo do processo.

"Valorizar a diversidade de saberes e vivências culturais e apropriar-se de conhecimentos e experiências que lhe possibilitem entender as relações próprias do mundo do trabalho e fazer escolhas alinhadas ao exercício da cidadania e ao seu projeto de vida, com liberdade, autonomia, consciência crítica e responsabilidade".

Outra consideração a ser feita com relação a importância do desenvolvimento de um projeto de vida, a fim de que o jovem seja protagonista de sua vida, é que "pesquisas realizadas com estudantes mostram a necessidade de essa etapa educacional adotar procedimentos que guardem maior relação com o projeto de vida dos estudantes como forma de ampliação da permanência e do sucesso dos mesmos na escola" (Diretrizes curriculares nacionais para o ensino médio, 2011, p. 155).

O programa de ensino integral instituído pela Lei Complementar $\mathrm{n}^{\circ} 1.164$, de 4 de janeiro de 2012 (BRASIL, 2012a) alterada pela Lei Complementar $n^{\circ}$ 1.191, de 28 de dezembro de 2012 (BRASIL, 2012b), “é uma alternativa para adolescentes e jovens ingressarem numa escola que, ao lado da formação necessária ao pleno desenvolvimento de suas potencialidades, amplia as perspectivas de autorrealização e exercício de uma cidadania autônoma, solidária e competente" (Diretrizes do programa ensino integral, 2014, p. 6 - 7).

A Lei 3415/2017 (BRASIL, 2017) que regulamenta a reforma do Ensino Médio apresenta a seguinte consideração no Art. 35-A:

$\S 7^{\circ}$ Os currículos do ensino médio deverão considerar a formação integral do aluno, de maneira a adotar um trabalho voltado para a construção de seu projeto de vida e para sua formação nos aspectos físicos, cognitivos e socioemocionais.

Para que o estudante construa o seu projeto de vida é importante que ele compreenda suas crenças e valores e que receba o apoio necessário para a efetivação do projeto. O apoio importante, pode ser permeado pela família, escola, comunidade. Essa construção se dará através da prática e vivência do protagonismo juvenil para promoção da autonomia, da liberdade. Isso implica em uma pedagogia que objetive nas circunstâncias materiais e históricas do sujeito, o caminho a ser percorrido, da relação entre o ser e o querer ser.

\section{Índices da Educação Brasileira}

A qualidade da aprendizagem nacional, com relação às etapas da Educação Básica, pode ser mensurada a partir de dados concretos obtidos por instrumentos avaliativos aplicados à estudantes (Sistema de Avaliação da Educação Básica - Saeb) e pela taxa de rendimento escolar (os índices de aprovação que são obtidos a partir do Censo Escolar realizado anualmente). O IDEB (Índice de Desenvolvimento da Educação Básica), criado em 2007, pelo Inep (Instituto Nacional de Estudos e Pesquisas Educacionais Anísio Teixeira) tem por objetivo medir a qualidade e estabelecer metas para a melhoria do ensino, permitindo o monitoramento da qualidade educacional pela população, para que haja mobilização em busca de melhorias.

O Saeb são o agrupamento de avaliações externas, em larga escala, que permeiam a realização de diagnóstico da educação básica brasileira e mapeiam fatores que interferem no desempenho estudantil. O Saeb apresenta os níveis de aprendizagem demonstrados pelos estudantes avaliados, explicando esses resultados a partir de uma série de informações contextuais.

Veja a Tabela que apresenta o IDEB até 2019, com valores propostos como meta a ser cumprida nos anos sinalizados em tabela. O índice varia de 0 a 10. 
Tabela 1. Tabela que apresenta o IDEB até 2019.

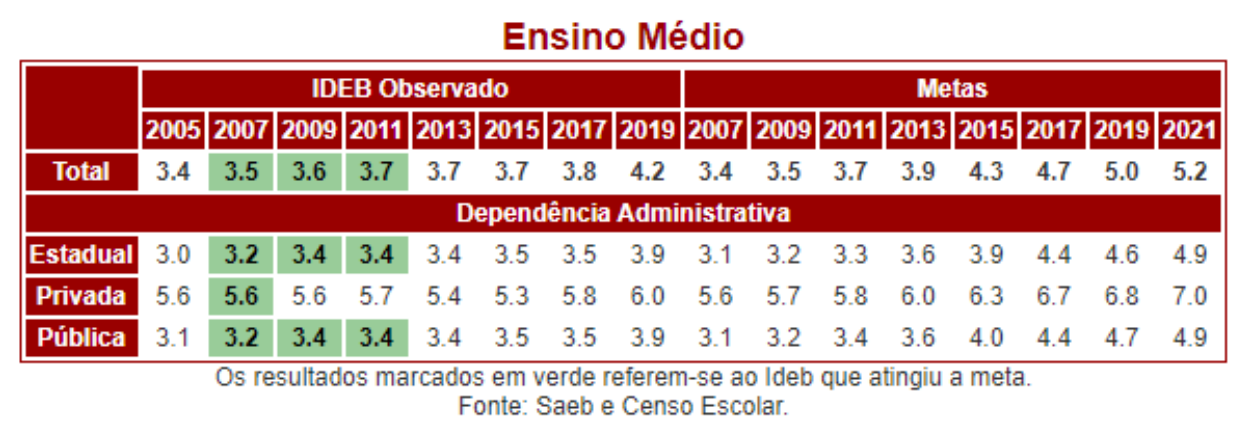

De acordo com os dados contidos na tabela do IDEB, é possível inferir que o Ensino Médio, apesar de apresentar uma discreta melhoria, ainda não tem atingido as metas estipuladas para cada ano. Repensar práticas pedagógicas adotadas em sala de aula, criar estratégias de aprendizagem para um processo mais personalizado, estipular metas para o desenvolvimento da aprendizagem, organizar o currículo e as formas de ofertas, atualizar as obrigatoriedades do sistema de ensino e da proposta pedagógica escolar, formar continuadamente seus educadores, investir em mudanças metodológicas no processo de ensino e aprendizagem, são ações que podem acarretar melhora na qualidade do ensino brasileiro e assim, permitir que as metas estipuladas pelo Plano Nacional de Educação sejam atingidas, para aproximar o Brasil ao IDEB de países desenvolvidos, qualificando integralmente seus estudantes.

As ações necessárias para a elevação do IDEB brasileiro compactuam com as propostas apresentadas pela Base Nacional Comum Curricular e pelas Diretrizes Curriculares Nacionais para o Ensino Médio, portanto ao se implementar o "Novo" Ensino Médio nas escolas brasileiras em 2022, se potencializará a elaboração e construção de Projeto de Vida, o que fomentará o protagonismo e autonomia estudantil e buscará a melhora na qualidade da educação básica.

\section{Metodologia}

O trabalho resulta da aplicação de um questionário, na qual buscou-se compreender o perfil do estudante contemporâneo, bem como a sua percepção quanto a importância do jovem desenvolver o projeto de vida e, ainda, relacionar o perfil do estudante contemporâneo com os desafios da sociedade atual e o Projeto vital individual.

Quanto à abordagem, é uma pesquisa qualitativa. Para Minayo (2001) a abordagem qualitativa responde às questões específicas. A metodologia qualitativa segundo Lakatus (2011), preocupa-se em analisar e interpretar aspectos mais profundos, descrevendo a complexidade do comportamento humano. Para essa pesquisa qualitativa fiz-se a coleta de dados, a fim de compreender a percepção dos estudantes diante de conceitos, princípios e significados. Para alcançar os objetivos desta pesquisa, escolheu-se estudantes de uma escola particular do Distrito Federal.

Participaram como sujeitos deste estudo 21 (vinte e um) estudantes matriculados em turmas do $1^{\circ}, 2^{\circ}$ e $3^{\circ}$ ano do Ensino Médio. No processo de coleta dos dados utilizou-se o critério de aplicação de um questionário para os vinte e um estudantes sobre o projeto de vida e o protagonismo estudantil.

\section{Resultados e Discussão}

O questionário aplicado foi composto por dezessete questões, sendo dezesseis de múltipla escolha e uma do tipo discursiva. Ao perguntar sobre o adolescente ser uma pessoa decidida e se importar com algo, obteve-se as respostas representadas nas seguintes imagens: 


\section{Figura 1.}

Sou uma pessoa decidida.

21 respostas

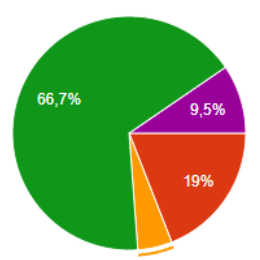

Discordo totalmente Discordo - Indiferente - concordo - Concordo plenamente
Existem coisas que realmente me importo.

21 respostas

Fonte: Autores (2021)

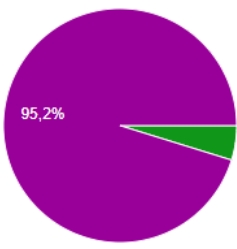

- Discordo totalmente

- Discordo

Indiferente

- Concordo

- Concordo plenament

Com as respostas fornecidas, percebe-se que 76,2\% dos adolescentes afirmam que são decididos e se importam com algo da vida. Quanto a importância, nas duas questões posteriores $100 \%$ dos jovens afirmam que se importam com sua família e $100 \%$ indicam se importar com o futuro pessoal (veja o gráfico abaixo). Essa importância que os estudantes atribuem revela que existe a preocupação com fatores integrantes do seu projeto de vida. Quando a importância se específica para futuro profissional, o percentual de jovens que concordam plenamente com essa afirmação aumenta ainda mais se comparado às outras duas perguntas. É o que mostram as imagens a seguir:

\section{Figura 2.}

Me importo com minha familia.

21 respostas

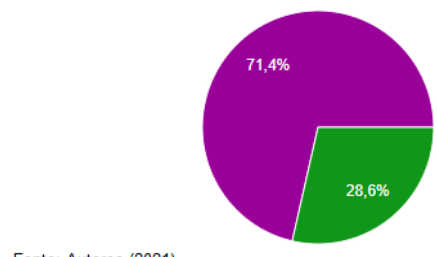

Fonte: Autores (2021)

Me importo com meu futuro profissional.

21 respostas
Me importo com o meu futuro pessoal.

21 respostas
- Discordo totalmente

Discordo

Indiferente

Concordo

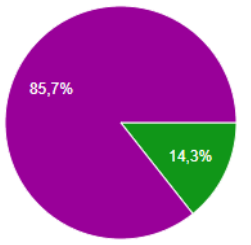

Discordo totalment

- Discordo

- Indiferente

- Concordo

- Concordo plenamente

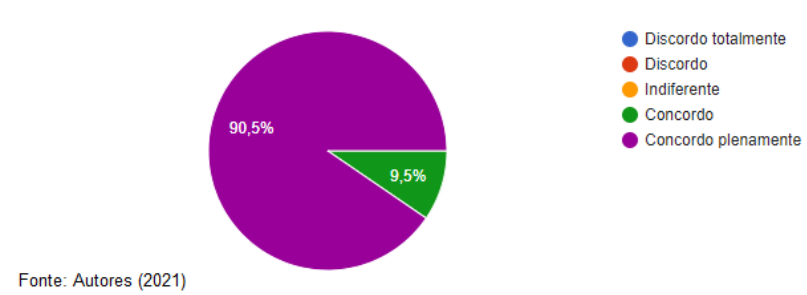

Sobre o jovem se perceber como uma pessoa decidida, que se importa com o presente e futuro pessoal e profissional, Damon (2009, p.23) afirma:

“[...] Alguns jovens de hoje saúdam essas mudanças e as novas oportunidades oferecidas. Eles têm aspirações claras para seu futuro. São fortemente motivados, cheios de energia, otimistas e criaram planos realistas para atingir suas ambições. Confiantes em si próprios, eles se divertem explorando o mundo e testando os limites de seu potencial. Longe de precisar de qualquer proteção ou estímulo, praticamente nada os detém. Em resumo, eles encontraram um projeto vital que os inspira e lhes dá direção". 
Quando questionados sobre objetivos de vida (veja gráfico abaixo), 90,5\% afirmaram ter objetivos a longo prazo e o mesmo percentual afirma que discordam ou discordam totalmente quanto a preferir não ter objetivos de vida, ou seja, a maioria dos jovens preferem ter objetivos e já os têm objetivos de longo prazo. Caso ainda não tenham esses objetivos definidos totalmente, mais de $85 \%$ dos jovens indicaram que concordam ou concordam plenamente que é importante se dedicar para conseguir alcançar seus objetivos de vida.

Com relação ao jovem, a determinação de objetivos, oportunidades e interesses, Damon (2009, p. 26) afirma que:

"Durante essa época-chave de transição para a idade adulta, é bom que os jovens gastem certo tempo examinando a si próprios, pensando no futuro e procurando as oportunidades que correspondem a seus interesses e ambições. Para muitos jovens, um período prolongado de exploração e reflexão durante a adolescência pode ser necessário para estabelecer uma autoidentidade satisfatória e um rumo positivo na vida".

Damon (2009, p.29) sinaliza ainda sobre dedicação que "Na maior parte das vezes o que falta à maioria dos jovens é o tipo de dedicação séria a uma atividade ou o interesse que vem de um projeto vital sincero, que pode dar significado e direcionamento à vida." Deve-se obervar as imagens:

Figura 3.

Tenho objetivos a longo prazo.

21 respostas

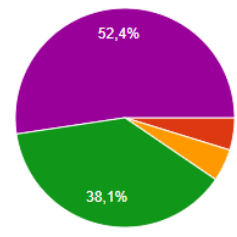

Discordo totalmente

Discordo

Indiferente

- Concordo

$38,1 \%$

Fonte: Autores (2021)

Me dedico para conseguir alcançar meus objetivos futuros, mesmo sem defini-los totalmente.

21 respostas

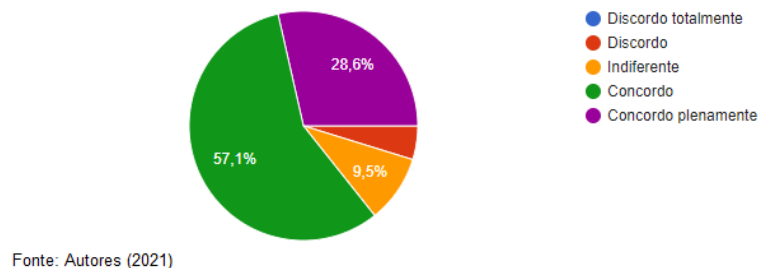

Fonte: Autores (2021)
Prefiro não ter objetivos de vida.

21 respostas

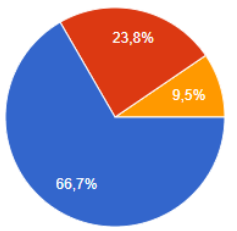

Discordo totalmen

- Discordo

concordo

- concordo prenamente

Com relação à importância da escola na definição dos objetivos de vida individuais, a imagem traz que cerca de $70 \%$ dos jovens afirmam que a escola os ajudou nessa escolha e 90,4\% visualizam o ambiente da escola como um espaço para engajamento, responsabilidade e autonomia, como mostrado nas próximas imagens: 


\section{Figura 4.}

A escola me ajudou e ajuda a definir meus objetivos de vida. 21 respostas

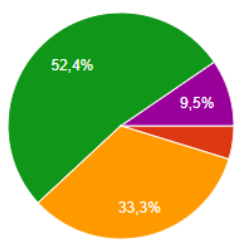

Fonte: Autores (2021)
A escola é um importante espaço para meu engajamento, responsabilidade e autonomia. 21 respostas

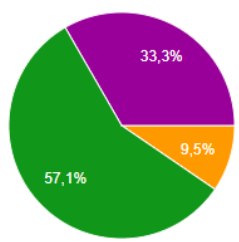

- Discordo totalmente

Discordo

Indiferen

conconos

Indiferente

concordo

Concordo plenamente

Ainda sobre o espaço da escola, quase 70\% dos respondentes afirmam que o desempenho escolar está diretamente ligado aos objetivos de vida, como mostra a imagem e $100 \%$ deles entendem que para e alcançar os objetivos do seu projeto de vida, é necessário esforço e dedicação.

\section{Figura 5.}

Meu desempenho escolar está diretamente ligado aos meus objetivos de vida. 21 respostas
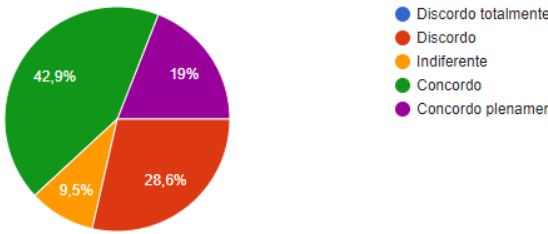

$$
\text { Discordo }
$$$$
\text { Indiferente }
$$

Concordo plenamente
Para alcançar meus objetivos preciso de esforço e dedicação. 21 respostas

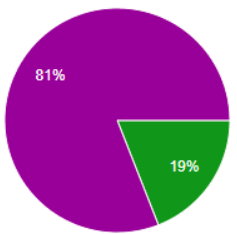

Discordo totalmente

Discordo

- Indiferente

Fonte: Autores (2021)

Cem por cento dos respondentes concordam plenamente ou concordam que é preciso estar engajado e ser responsável àquilo que se propõem a fazer. Mesmo sendo difícil apresentar essas características o tempo todo, o projeto vital futuro os motiva a permanecerem dedicados, como se pode observar nas imagens:

Figura 6.

Para alcan

21 respostas

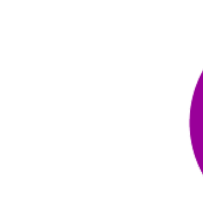

Fonte: Autores (2021)

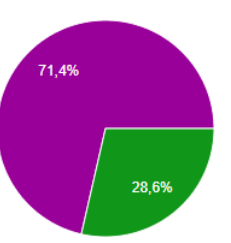

Discordo totalmente

Discordo

- Indiferente

- concordo

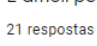

21 respostas

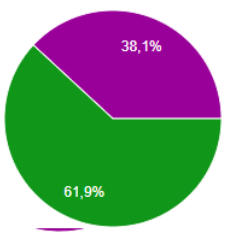

Discordo totalment

- Discordo

- concordo

Concordo plenamente

Nas imagens, há referência quanto ao envolvimento de outras pessoas, além dos próprios estudantes, $57,1 \%$ afirmam que outras pessoas se envolvem nos seus esforços e quanto às situações cotidianas desafiadoras $76,2 \%$ dos estudantes afirmam que diante dessas situações se motivam e tentam resolver. 


\section{Figura 7.}

Outras pessoas se envolvem em meus esforços.

21 respostas

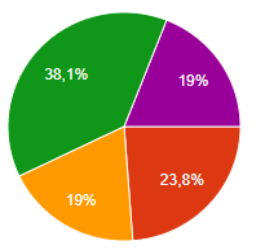

Quanto a sua postura diante das situações e desafios rotineiros, como lida com essas circunstâncias, 21 respostas

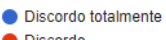

Discordo

Indiferente

- Concordo

- Concordo plenamente

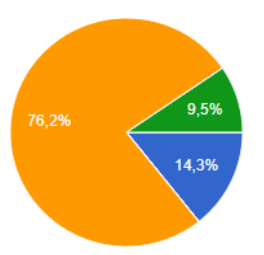

- Não me sinto motivado para resolver

nenhuma situação.

Se não tiver relação direta comigo, nem

tento resolver.

Enriento, me motivo e tento resolver

- Desisto facilmente

- Não me interesso.

Fonte: Autores (2021)

Para compactuar com as respostas dos discentes com relação às últimas perguntas do questionário, Damon (2009, p.43) argumenta que "Um propósito pode organizar uma vida inteira, concedendo-lhe não apenas significado, como também inspiração e motivação para o aprendizado contínuo e realização".

\section{Conclusão}

Os jovens estudantes que responderam o questionário para a construção desta pesquisa já vivenciam em sua prática cotidiana, seja no ambiente da escola ou em parceria com as famílias, a construção de seus projetos vitais. Dessa forma, eles conseguem descobrir seus projetos de vida, baseados nos seus interesses e crenças. Esses adolescentes refletem sobre seu projeto de vida, isso favorece que além das mudanças quanto ao engajamento, dedicação, motivação, postura frente ao cotidiano, ocorra a formação da identidade dele. Essa formação identitária propicia que os jovens sejam menos indecisos, ansiosos, confusos na busca de objetivos, estejam sem direção a seguir. Neste caso, oportunidades são perdidas, podem surgir hábitos negativos. Não há um tempo exato para que o indivíduo tome direção na vida, mas um atraso na escolha dela pode acarretar desistência na procura de caminhos positivos, ausência de metas, descomprometimento com a carreira profissional, vida, família. Acabam dependendo da sorte para encontrar caminhos que os façam felizes e realizados.

Corroborando com esta ideia, Damon (2009, p.31) afirma que:

“[...] Certamente a falta desse projeto pode ser compatível com hedonismo, e muitos jovens sem compromisso relatam que estão se divertindo. Mas conforme a descoberta de psicólogos que recentemente estudaram a felicidade, os momentos de prazer hedonista que as pessoas sem compromisso vivenciam duram pouco e são basicamente vazios, especialmente se comparados ao tipo de satisfação mais duradoura e gratificante que o psicólogo Martin Seligman chamou de "felicidade autêntica".

O projeto de vida propicia ao jovem um presente e futuro bem planejados de acordo com seus interesses, desejos, habilidades. Por conta dele percebe-se jovens motivados, comprometidos, com um sentido positivo que lhes dá significado à vida.

E para este autor "o que importa para a felicidade é o comprometimento com algo que a pessoa considere envolvente, desafiador e atraente, especialmente quando ela faz uma valiosa contribuição ao mundo" (Damon 2009, p.49). De acordo com a participação dos estudantes no questionário fica evidente que a maior parte deles se preocupam, dedicam, motivam para o seu projeto de vida futuro. Mesmo não sabendo, muitas vezes, o que desejam executar pessoal e profissionalmente, compreendem que é preciso se engajar, ser autônomo e protagonista na caminhada de construção e reconstrução do projeto de vida individual. 
Research, Society and Development, v. 11, n. 1, e39511125070, 2022

(CC BY 4.0) | ISSN 2525-3409 | DOI: http://dx.doi.org/10.33448/rsd-v11i1.25070

\section{Referências}

Bassalobre, J. (2013). Formação de professores, ética e responsabilidade social. 18(15), jan./jun.

Boghossian, C. O. \& Minayo, M. C. S. Revisão sistemática sobre juventude e participação nos últimos 10 anos. Saúde e Sociedade, São Paulo, 18(3).

Brasil. (1996). Lei no 9.394 de 20 de dezembro de 1996. Estabelece As Diretrizes E Bases da Educação Nacional (LDB). Presidência da República, Brasília: DF, 1996. http://www.planalto.gov.br/ccivil_03/leis/19394.htm. Acesso em 21 set. 2021.

Brasil. (1996). Lei Federal 13.415, de 16 de fevereiro de 2017. Altera as Leis ${ }^{\circ}{ }^{\circ}$ 9.394, de 20 de dezembro de 1996 , que estabelece as diretrizes e bases da educação nacional, e 11.494, de 20 de junho 2007, que regulamenta o Fundo de Manutenção e Desenvolvimento da Educação Básica e de Valorização dos Profissionais da Educação, a Consolidação das Leis do Trabalho - CLT, aprovada pelo Decreto-Lei n ${ }^{\circ} 5.452$, de $1^{\circ}$ de maio de 1943 , e o Decreto-Lei no 236 , de 28 de fevereiro de 1967; revoga a Lei n ${ }^{\circ} 11.161$, de 5 de agosto de 2005; e institui a Política de Fomento à Implementação de Escolas de Ensino Médio em Tempo Integral. Presidência da República, Brasília: DF, 2017. Disponível em: http://www.planalto.gov.br/ccivil_03/_ato2015-2018/2017/lei/113415.htm. Acesso em: 08 out. 2021.

Damon, W. (2009). O que o jovem quer da vida? Como pais e professores podem orientar e motivar os adolescentes. São Paulo: Summus, 2009.

Dowbor, L. (2013). Tecnologias do conhecimento os desafios da educação. Outubro 2013.

https://www.academia.edu/3387227/Tecnologias_do_conhecimento_os_desafios_da_educa\%C3\%A7\%C3\%A3o>

Fava, R. (2018). Trabalho, educação e inteligência artificial: a era do indivíduo versátil. Penso.

Freire, P. (1987). Pedagogia do oprimido. (17 ed.) Paz e Terra.

Freire, P. (2014). Pedagogia da autonomia saberes necessários à prática educativa Freire. (25ª ed.). Paz e Terra Coleção Leitura.

Papalia, D. E. \& Feldman, R. D. (Colab.).(2013). Desenvolvimento Humano. (12 a ed.). AMGH Editora, 2013.

Marconi, M. A \& Lakatos, E. M. (2011). Metodologia Científica. (6 ${ }^{\text {a }}$ ed.). Atlas,. p. 269-289.

MEC. (2018). Ministério da Educação. Base Nacional Comum Curricular (BNCC). Brasília/DF: 2018. http://basenacionalcomum.mec.gov.br/images/BNCC_EI_EF_110518_versaofinal_site.pdfAcesso em: 09 out. 20021.

Moraes, R. Galliazi, M. C. (2016). Análise Textual Discursiva. (3 ed.) Editora Unijuí, 264p. E-book ISBN 978-65-86074-19-2

Minayo, M. C. S. (org). (2001). Pesquisa Social. Teoria, método e criatividade. (18 ed.). Vozes.

Moram, J. (2021). A importância de construir projetos de vida na educação. Setembro 2017. www2.eca.usp.br/moran.

Reeve, J. (2009). Why teachers adopt a controlling motivating style toward students and how they can become more autonomy supportive. Educational Psychologist, Hillsdale, 44(3), 159-175.

Tecnologies, D. Concretizando 2030: o futuro do trabalho. https://www.dellemc.com/content/dam/uwaem/production-designassets/en/CSG/collateral/pt/2030_Report_WFT_Portuguese.pdf> 